\title{
Produção de poligalacturonase, pelo termofílico Bacillus sp. e algumas de suas propriedades
}

\author{
Production of a polygalacturonase, by thermophilic Bacillus sp. and some properties of the enzyme
}

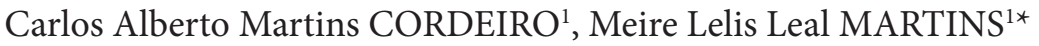

\begin{abstract}
Resumo
A produção de poligalacturonase pelo termofílico Bacillus sp. SMIA-2, cultivado em meio líquido contendo pectina cítrica como única fonte de carbono, alcançou a sua máxima atividade enzimática em 30 horas, com níveis de $42 \mathrm{IU} \cdot \mathrm{mL}^{-1}$. Entre as várias fontes orgânicas e inorgânicas de nitrogênio testadas, o sulfato de amônio foi a que proporcionou maior atividade da poligalacturonase. O aumento da concentração da pectina cítrica, no meio de cultura, acima de $0,5 \%$ não proporcionou um aumento da atividade da enzima. O microrganismo foi capaz de utilizar uma variedade de fontes de carbono, mas a atividade da poligalacturonase variou com cada fonte. Pectina de maçã foi a melhor fonte de carbono para a secreção da poligalacturonase $\left(56 \mathrm{IU} \cdot \mathrm{mL}^{-1}\right)$, enquanto frutose e maltose não foram muito efetivas. Galactose, rafinose e glicose inibiram a síntese da enzima. Estudos sobre a caracterização da poligalacturonase revelaram que a temperatura ótima dessa enzima foi $70{ }^{\circ} \mathrm{C}$ e que ela manteve 62 e $58 \%$ de sua atividade máxima quando incubada por 2 horas a 40 e $90{ }^{\circ} \mathrm{C}$, respectivamente. $\mathrm{O}$ pH ótimo para atividade da enzima foi 7,0. A enzima manteve 90 e $75 \%$ de sua atividade máxima quando incubada a pH 8,0 e 8,5, respectivamente,

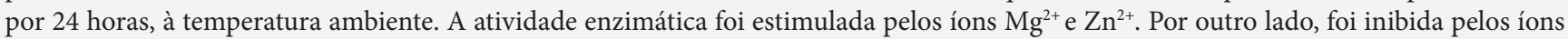
$\mathrm{Cs}^{+2}, \mathrm{Hg}^{+2}, \mathrm{Li}^{+2}$ e $\mathrm{Sr}^{+2}$.

Palavras-chave: poligalacturonase; bactéria termofílica; Bacillus sp.
\end{abstract}

\begin{abstract}
Polygalacturonase production by thermophilic Bacillus sp strain SMIA-2 cultivated in liquid media containing citrus pectin as a carbon source reached the maximum activity at 30 hour with levels of $42 \mathrm{IU} \cdot \mathrm{mL}^{-1}$. Among the various organic and inorganic nitrogen sources, ammonium sulphate was found to be the best for the enzyme secretion. An increase in the citrus pectin concentration in the medium of more than $0.5 \%$ did not enhance enzyme synthesis. The microorganism was capable of utilizing a wide range of carbon sources, but the activity of poligalacturonase varied depending on the carbon source. Apple's pectin was the best carbon source in the present study for polygalacturonase secretion (56 IU. $\mathrm{mL}^{-1}$ ) while fructose and maltose were not very effective. Rafinose and glucose inhibited the enzyme synthesis. Studies on the polygalacturonase characterization revealed that the optimum temperature of this enzyme was $70{ }^{\circ} \mathrm{C}$ and that it maintained 62 and $58 \%$ of its activity when incubated at $40{ }^{\circ} \mathrm{C}$ and $90{ }^{\circ} \mathrm{C}$ for 2 hour, respectively. The optimum pH of the enzyme was found to be 7.0 . The enzyme maintained $90 \%$ and $75 \%$ of its maximal activity when incubated at $\mathrm{pH} 8.0$ and 8.5 for 24 hour at room temperature, respectively. The enzyme activity was enhanced in the presence of $\mathrm{Mg}^{2+}$ and $\mathrm{Zn}^{2+}$. On the other hand, the activity was inhibited in the presence of $\mathrm{Cs}^{+2}, \mathrm{Hg}^{+2}, \mathrm{Li}^{+2}$ and $\mathrm{Sr}^{+2}$.

Keywords: polygalacturonase; thermophilic bacterium; Bacillus sp.
\end{abstract}

\section{Introdução}

Enzimas pectinolíticas são amplamente usadas em várias indústrias. $\mathrm{Na}$ de alimentos, essas enzimas atuam na extração, despectinização e clarificação de sucos de frutas (banana, mamão, maçã) e vinho, na extração de óleo vegetal, bem como na produção de alimentos para bebês (BUENROSTRO; LOPES-MUNGUIA, 1986; GHILDYAL et al., 1981; GUPTA et al., 2007; KASHYAP et al., 2001; NIGHOJKAR et al., 2006; USTOK; TARI; GOGUS, 2007). Podem ser utilizadas também na indústria de fermentados, como, por exemplo, na fermentação do cacau, café e do fumo, e na degomagem de fibras naturais (BRAVO et al., 2000; FAWOLE; ODUNFA, 2003; GENARI, 1999).

As enzimas pécticas são classificadas em pectinesterase e despolimerase, sendo que esta última é subdividida em hidrolases e liases. As poligalacturonases são hidrolases que atuam mais em pectato que em pectina e resultam em mono ou dissacarídeos. Quanto aos mecanismos de ação sobre o substrato, essas enzimas são classificadas em dois grupos: endopoligalacturonase, que promovem a hidrólise ao acaso da cadeia de pectato (endo-PG, E.C.3.2.1.15), e exopoligalacturonase, que hidrolisam a cadeia de pectato a partir da extremidade não redutora (exo-PG, E.C.3.2.1.67) (KASHYAP et al., 2001; SAKAI et al., 1993).

Enzimas pectionolíticas podem ser sintetizadas por bactérias, fungos e leveduras. A produção de pectinases por microrganismos é influenciada pelas condições de cultivo, em particular, pela composição do meio de cultura, tipo e concentração da fonte de carbono, $\mathrm{pH}$ e temperatura do cultivo, além de outros fatores (BRAVO et al., 2000; FREITAS, 1991). Assim, o primeiro

Recebido para publicação em 17/8/2007

Aceito para publicação em 14/1/2008 (002733)

Laboratório de Tecnologia de Alimentos, Centro de Ciências e Tecnologias Agropecuárias, Universidade Estadual do Norte Fluminense - UENF, Av. Alberto Lamego, 2000, CEP 28015-620, Campos dos Goytacazes - RJ, Brasil, E-mail: meire@uenf.br

${ }^{*}$ A quem a correspondência deve ser enviada 
passo para a utilização industrial destas enzimas é a seleção ou o desenvolvimento de estirpes adequadas, seguida pela otimização das condições de cultivo, ou seja, conhecer os diversos aspectos que regulam a síntese e a atividade da enzima.

A maior parte das pesquisas envolvendo a produção de pectinases está relacionada com microrganismos mesofílicos (CONTRERAS-ESQUIVEL; VOGET, 2004; FAWOLE; ODUNFA, 2003; NITURE; PANT, 2004). Entretanto, enzimas de microrganismos termofílicos têm recebido considerável atenção da indústria por causa de suas características especiais, como estabilidade térmica e às altas mudanças de $\mathrm{pH}$. Por isso, podem ser usadas em diversos processos industriais nos quais substituem as enzimas produzidas por microrganismos mesofílicos ou produtos químicos. As principais vantagens do uso dessas enzimas em processos conduzidos a altas temperaturas são: redução do risco de contaminação microbiana; menor viscosidade - a maior parte dos reagentes torna-se mais solúvel, difundindo-se mais rapidamente e, assim, permitindo que concentrações maiores desses compostos possam ser utilizadas -; aumento da taxa de transferência de massa e da solubilidade dos substratos (AGUILAR, 1996; ARCHANA; SATYANARAYANA, 1997; BRUINS; JANSSEN; BOOM, 2001; HAKI; RAKSHIT, 2003; LEE et al., 2001).

Apesar dessas vantagens que as enzimas termofílicas oferecem para o uso rotineiro na indústria, a aplicação biotecnológica de microrganismos termofílicos tem sido muito limitada até agora. As razões para esta contradição são muitas, mas a principal delas está relacionada com o escasso número de linhagens termofílicas para a pesquisa de enzimas termoestáveis específicas, disponíveis em coleções. A maioria das bactérias termofílicas investigadas pertence ao gênero Bacillus e foram isoladas de ambientes termofílicos e mesofílicos (BRUINS; JANSSEN; BOOM, 2001).

Considerando o exposto, o presente trabalho teve como objetivo avaliar a produção de poligalacturonases por um microrganismo termofílico, Bacillus sp. SMIA-2. O efeito da temperatura, do $\mathrm{pH}$ e de alguns íons sobre a atividade e estabilidade da enzima foram também investigados.

\section{Material e métodos}

\subsection{Microrganismo e condições da cultura}

O microrganismo usado neste estudo foi uma bactéria termofílica, Bacillus sp. cepa SMIA-2 (NUNES; MARTINS, 2001), previamente isolada de amostras de solo coletadas na cidade de Campos dos Goytacazes, Rio de Janeiro, Brasil. O microrganismo foi mantido em tubos de ensaio contendo meio TSY (triptona 20 g. $\mathrm{L}^{-1}$; $\mathrm{NaCl} 10$ g.L $\mathrm{L}^{-1}$; extrato de levedura 10 g.L. ${ }^{-1}$; ágar 20 g.L. L $^{-1}$ e água 1 L), sob temperatura de refrigeração. Para a produção da poligalacturonase, o seguinte meio de cultura foi utilizado: Pectina cítrica - 5,0 g; $\mathrm{NaH}_{2} \mathrm{PO}_{4} \cdot 2 \mathrm{H}_{2} \mathrm{O}-1,56 \mathrm{~g} ; \mathrm{NH}_{4} \mathrm{Cl}-5,35 \mathrm{~g} ; \mathrm{KCl}-0,745 \mathrm{~g}$; $\mathrm{Na}_{2} \mathrm{SO}_{4} \cdot 10 \mathrm{H}_{2} \mathrm{O}-0,644 \mathrm{~g}$; Ácido cítrico - 0,42 g; $\mathrm{MgCl}_{2} \cdot 6 \mathrm{H}_{2} \mathrm{O}-$ $0,25 \mathrm{~g} ; \mathrm{CaCl}_{2}-2,2 \times 10^{-3} \mathrm{~g} ; \mathrm{ZnO}-2,5 \times 10^{-3} \mathrm{~g} ; \mathrm{FeCl}_{3} \cdot 6 \mathrm{H}_{2} \mathrm{O}-$ $2,7 \times 10^{-2} \mathrm{~g} ; \mathrm{MnCl}_{2} \cdot 4 \mathrm{H}_{2} \mathrm{O}-1,0 \times 10^{-2} \mathrm{~g} ; \mathrm{CuCl}_{2} \cdot 2 \mathrm{H}_{2} \mathrm{O}-8,5 \times$ $10^{-4} \mathrm{~g} ; \mathrm{CoCl}_{2} \cdot 6 \mathrm{H}_{2} \mathrm{O}-2,4 \times 10^{-3} \mathrm{~g} ; \mathrm{NiCl}_{3} \cdot 6 \mathrm{H}_{2} \mathrm{O}-2,5 \times 10^{-4} \mathrm{~g}$; $\mathrm{H}_{3} \mathrm{BO}_{3}-3,0 \times 10^{-4}$ ge $\mathrm{Na}_{2} \mathrm{MoO}_{4}-1,0 \times 10^{-3} \mathrm{~g}$, dissolvidos em
1 L de água destilada (EVANS; HERBERT; TEMPEST, 1970). $\mathrm{O}$ pH foi ajustado para 7,5 com 1,0 $\mathrm{M} \mathrm{NaOH}$, e este meio foi esterilizado em autoclave a $121 \pm 2{ }^{\circ} \mathrm{C}$ por 15 minutos. A pectina cítrica foi esterilizada separadamente e adicionada assepticamente ao meio de crescimento.

O inóculo foi preparado semeando o microrganismo em placas de petri contendo o meio TSY. As placas foram incubadas em estufa QUIMIS modelo Q $315 \mathrm{D} 26$ a $50{ }^{\circ} \mathrm{C}$ por 18 horas. Após este período, $10 \mathrm{~mL}$ do meio de crescimento foram transferidos para as placas para ressuspender as células, que foram posteriormente sugadas com o auxílio de uma pipeta estéril. Estas células foram inoculadas em frascos erlenmeyers de $250 \mathrm{~mL}$ contendo $50 \mathrm{~mL}$ do respectivo meio de crescimento, incubadas por mais 18 horas a $50{ }^{\circ} \mathrm{C}$ e posteriormente utilizadas para inocular o meio de produção.

O meio de produção, inoculado com $1 \mathrm{~mL}$ de uma cultura de véspera, foi incubado em um agitador Thermo Forma Orbital Shaker (Ohio, USA), a $150 \mathrm{rpm}$ em temperatura de $50^{\circ} \mathrm{C}$ por 66 horas. Os experimentos foram realizados com três repetições, sendo cada uma constituída por $50 \mathrm{~mL}$ de meio de cultura, em erlenmeyer de $250 \mathrm{~mL}$. A intervalos de tempo determinados, foram retirados três frascos para medida da densidade ótica, a 470 nm (NUNES; MARTINS, 2001), que consistiu na utilização de um espectrofotômetro Hitachi modelo U-2000; pH e determinação da atividade da enzima.

\subsection{Ensaio enzimático}

Para a remoção das células, o meio de cultura foi centrifugado a 4500 g por 15 min a $4{ }^{\circ} \mathrm{C}$ em uma centrífuga modelo HERMLE Z 382 K (Wehingen, Alemanha) e o sobrenadante livre de células, utilizado para dosagem da atividade da enzima. A atividade enzimática foi determinada em amostras em triplicata, pela quantificação de açúcares redutores (galacturônico) através do método de Miller (1959).

Uma mistura contendo $0,2 \mathrm{~mL}$ da preparação enzimática (sobrenadante livre de células) e $0,8 \mathrm{~mL}$ de solução de pectina cítrica a $0,5 \%$ dissolvida em tampão fosfato $(50 \mathrm{mM}, \mathrm{pH} 7,0)$ foi incubada a $70^{\circ} \mathrm{C}$ por 10 minutos (SAKAI et al., 1993). Após esse período, a reação foi paralisada pela adição de $1,0 \mathrm{~mL}$ de ácido 3,5-dinitrossalicílico (DNS) à mistura, que foi rapidamente resfriada em água gelada. Em seguida, esta mistura foi colocada em água em ebulição por 10 minutos e resfriada em banho de gelo. A coloração desenvolvida foi medida por meio de espectrofotômetro SHIMADZU UV-mini 1240, utilizando comprimento de onda de $540 \mathrm{~nm}$. O mesmo procedimento foi realizado com o controle, exceto que o reagente de Miller foi adicionado juntamente com a enzima à solução de pectina cítrica $0,5 \%$, e esta mistura foi colocada em água em ebulição como descrito anteriormente. Uma unidade de poligalacturonase foi definida como a quantidade de enzima necessária para produzir $1 \mu \mathrm{mol}$ de ácido galacturônico por minuto a partir da pectina cítrica nas condições do ensaio.

\subsection{Efeito das condições de cultivo sobre a atividade da enzima}

As seguintes fontes de nitrogênio (1\%): extrato de levedura, extrato de carne, peptona, caseína, citrato de amônio, uréia, 
$\mathrm{KNO}_{3},\left(\mathrm{NH}_{4}\right)_{2} \mathrm{SO}_{4}, \mathrm{NH}_{4} \mathrm{Cl},\left(\mathrm{NH}_{4}\right)_{2} \mathrm{HPO}_{4}, \mathrm{NH}_{4} \mathrm{NO}_{3}$, foram acrescidas individualmente ao meio de cultura para avaliar o crescimento do microrganismo e a atividade da poligalacturonase. Além disso, várias concentrações de pectina cítrica $(0,05-1,0 \%)$ foram utilizadas no meio para avaliar a atividade da enzima. A influência da fonte de carbono sobre o crescimento do microrganismo e a atividade da poligalacturonase foram investigadas substituindo a pectina cítrica do meio de cultura pelas seguintes fontes de carbono, a $0,5 \%$ : frutose, galactose, glicose, rafinose, maltose e pectina de maçã.

\subsection{Caracterização parcial da enzima}

Ao sobrenadante livre de células, foi adicionado o equivalente a $60 \%$ de sulfato de amônio para a precipitação proteica. Após esse procedimento, o material precipitado foi centrifugado a $20.600 \mathrm{~g}$ por 10 minutos a $4{ }^{\circ} \mathrm{C}$. Ao precipitado, foi adicionada uma quantidade mínima de tampão fosfato para sua ressuspensão, sendo novamente centrifugado em centricon de 30 a 20.600 g por 20 minutos a $4{ }^{\circ} \mathrm{C}$ e o filtrado utilizado para dosagem da atividade da enzima.

\section{Efeito da temperatura na atividade e estabilidade da poligalacturonase}

A determinação da temperatura ótima foi realizada incubando-se a mistura de reação $(\mathrm{pH} 7,0)$ a temperaturas que variaram de 40 a $100{ }^{\circ} \mathrm{C}$, com intervalos de $10{ }^{\circ} \mathrm{C}$. Depois de 10 minutos de incubação, em cada temperatura, a atividade enzimática foi analisada.

A estabilidade térmica foi avaliada incubando-se a enzima a temperaturas que variaram de 30 a $100{ }^{\circ} \mathrm{C}$, com intervalos de $10^{\circ} \mathrm{C}$. Após duas horas de incubação, a atividade residual foi analisada à temperatura ótima da enzima, determinada anteriormente.

Efeito do pH sobre a atividade e estabilidade da poligalacturonase

A influência do $\mathrm{pH}$ sobre a atividade de poligalacturonase foi avaliada na faixa de 5,0 a 10,0 com intervalo de 0,5 unidades. Utilizou-se para o preparo do substrato uma mistura tamponante contendo acetato de sódio ( $\mathrm{pH} 5,0-5,5)$, fosfato $(\mathrm{pH} \mathrm{6,0-8,0)} \mathrm{e}$ tris ( $\mathrm{pH} 8,5-10,0)$, na concentração final de $50 \mathrm{mM}$. Os valores de $\mathrm{pH}$ da mistura da reação foram ajustados com $\mathrm{NaOH}$ ou $\mathrm{HCl} 1 \mathrm{~N}$.

$\mathrm{O}$ pH ótimo foi determinado pela incubação de $0,2 \mathrm{~mL}$ da enzima e $0,8 \mathrm{~mL}$ de pectina cítrica $(0,5 \%)$ preparada em tampão com diferentes valores de $\mathrm{pH}$. Depois de incubação a $70{ }^{\circ} \mathrm{C}$ por 10 minutos, foi analisada a atividade enzimática conforme descrita anteriormente.

A estabilidade da poligalacturonase sob diferentes valores de $\mathrm{pH}$ foi avaliada incubando-se o extrato enzimático nos tampões anteriormente descritos, sem o substrato, por 2 horas à temperatura ambiente. Após este tratamento, a atividade residual da poligalacturonase foi determinada conforme descrita anteriormente.
Efeito de ions sobre a atividade da poligalacturonase

Para estudar o efeito de diferentes íons metálicos na atividade da poligalacturonase, foram adicionados à mistura de reação os seguintes compostos, a uma concentração final de $1 \mathrm{mM}$ : $\mathrm{CaCl}_{2}, \mathrm{BaCl}_{2}, \mathrm{AgNO}_{3}, \mathrm{HgCl}_{2}, \mathrm{CuSO}_{4}, \mathrm{ZnSO}_{4}, \mathrm{CsCl}, \mathrm{CoSO}_{4}$, $\mathrm{NiCl}_{2}, \mathrm{C}_{4} \mathrm{H}_{6} \mathrm{O}_{4} \mathrm{~Pb}, \mathrm{FeSO}_{4}, \mathrm{MnSO}_{4}, \mathrm{MgSO}_{4}, \mathrm{SrCl}_{2} \mathrm{e} \mathrm{LiSO}_{4}$. A atividade enzimática residual (\%) foi determinada nas condições anteriormente descritas. Um controle (ausência de metais) foi considerado como $100 \%$ de atividade.

\subsection{Análise estatística}

Os experimentos foram conduzidos em triplicata, e os resultados avaliados pela análise de variância (ANOVA) utilizando o programa SAS. Os efeitos dos tratamentos foram comparados pelo teste de Tukey.

\section{Resultados e discussão}

\subsection{Crescimento do Bacillus sp. SMIA-2 e produção da poligalacturonase}

Bacillus sp. SMIA-2 cresceu e secretou poligalacturonase quando cultivado no meio de cultura contendo pectina cítrica $(0,5 \%)$ como única fonte de carbono (Figura 1). O crescimento do microrganismo e a síntese da enzima foram iniciados imediatamente após a incubação do meio de cultura. A atividade máxima da poligalacturonase foi observada após 30 horas de incubação da cultura, quando o crescimento do microrganismo já havia cessado. Subsequentemente, os níveis da enzima permaneceram mais ou menos os mesmos até 42 horas e, então, caíram para aproximadamente $30 \mathrm{IU} \cdot \mathrm{mL}^{-1} \mathrm{em} 66$ horas.

Durante as primeiras 6 horas de incubação da cultura, foi observada uma queda do $\mathrm{pH}$ do meio de cultura de 6,87 para

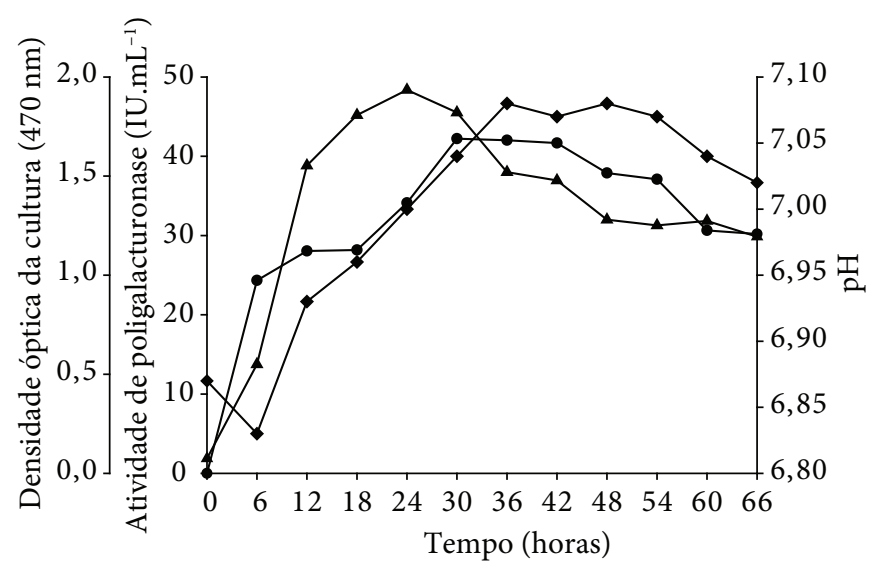
(৯) Densidade da cultura $(470 \mathrm{~nm})$
$(\bullet)$ Atividade de poligalacturonase
(-) $\mathrm{pH}$

Figura 1. Crescimento e atividade da poligalacturonase secretada por Bacillus sp. SMIA-2 cultivado em $0,5 \%$ de pectina cítrica, a $50{ }^{\circ} \mathrm{C}$. 
6,83 . Essa queda inicial do $\mathrm{pH}$ do meio pode ser devido à produção de ácidos durante a fermentação da fonte de carbono, que é mais intensa nesse período. Em seguida, o pH do meio aumentou gradativamente para 7,08 depois de 36 horas de incubação da cultura e permaneceu praticamente sem alterações até 54 horas e, então, decresceu. A elevação do pH do meio pode ser atribuída à utilização dos ácidos orgânicos ou produção de componentes alcalinos durante esse período de tempo. Segundo Ming Chu (1992), a acidificação ou alcalinização do meio de cultura reflete o consumo de substrato. Quando íons amônio estão sendo utilizados, o meio torna-se mais ácido e, quando nitrogênio orgânico (aminoácidos e peptídeos) está sendo assimilado, o meio torna-se mais alcalino. Devido a essa relação entre a síntese de poligalacturonase e a utilização de compostos nitrogenados, a variação do $\mathrm{pH}$ pode ser utilizada para fornecer informações importantes sobre a produção de poligalacturonases, como o início e o final de sua síntese.

\subsection{Influência da composição do meio de cultura sobre a atividade da poligalacturonase}

Entre as várias fontes de nitrogênio que foram testadas, o sulfato de amônio foi a que proporcionou maior atividade da poligalacturonase (Tabela 1). Bons níveis de atividade enzimática foram obtidos quando a peptona, citrato de amônio e uréia foram utilizados como fonte de nitrogênio. Esses resultados contrastam com os encontrados por Kelly e Fogart (1978) para o Bacillus sp. RK9, em que níveis mais altos de atividade da poligalacturonase foram encontrados para compostos nitrogenados complexos, que produziram altos níveis de biomassa, tais como extrato de levedura e peptona. De um modo geral, na produção de enzimas em larga escala, não somente a fonte de nitrogênio, mas seu preço deve ser considerado na seleção da melhor fonte. Desta maneira, a utilização do sulfato de amônio, além de proporcionar maiores atividades da poligalacturonase, é uma fonte economicamente viável.

Uma ascensão do crescimento do microrganismo foi observada à medida que se aumentou a concentração da pectina cítrica no meio de cultura. Entretanto, em relação à atividade

Tabela 1. Influência da fonte de nitrogênio sobre o crescimento de Bacillus sp. SMIA-2 e a atividade da poligalacturonase.

\begin{tabular}{lcc}
\hline Fonte de nitrogênio & $\begin{array}{c}\text { Atividade máxima da } \\
\text { enzima }\left(\mathrm{IU} \cdot \mathrm{mL}^{-1}\right)\end{array}$ & $\begin{array}{c}\text { Densidade ótica } \\
(470 \mathrm{~nm})\end{array}$ \\
\hline Sulfato de amônio & $41,6 \pm 2,654^{\mathrm{a}}$ & $1,3 \pm 0,064^{\mathrm{e}, \mathrm{f}}$ \\
Nitrato de potássio & $28,2 \pm 2,360^{\mathrm{b}, \mathrm{c}}$ & $1,3 \pm 0,147^{\mathrm{e}, \mathrm{f}}$ \\
Nitrato de amônio & $16,4 \pm 2,579^{\mathrm{d}, \mathrm{e}, \mathrm{f}}$ & $1,5 \pm 0,009^{\mathrm{c}, \mathrm{d}, \mathrm{e}}$ \\
Fosfato de amônio & $15,5 \pm 2,441^{\mathrm{d}, \mathrm{e}, \mathrm{f}}$ & $1,4 \pm 0,240^{\mathrm{e}, \mathrm{f}}$ \\
Citrato de amônio & $26,5 \pm 1,604^{\mathrm{b}, \mathrm{c}, \mathrm{d}}$ & $1,7 \pm 0,103^{\mathrm{b}, \mathrm{c}, \mathrm{d}}$ \\
Cloreto de amônio & $14,9 \pm 1,359^{\mathrm{e}, \mathrm{f}}$ & $1,8 \pm 0,183^{\mathrm{a}, \mathrm{b}, \mathrm{c}}$ \\
Extrato de carne & $10,6 \pm 0,560^{\mathrm{f}}$ & $2,1 \pm 0,076^{\mathrm{a}, \mathrm{b}}$ \\
Extrato de levedura & $19,7 \pm 1,812^{\mathrm{b}, \mathrm{c}, \mathrm{d}, \mathrm{f}}$ & $1,8 \pm 0,204^{\mathrm{a}, \mathrm{b}, \mathrm{c}, \mathrm{d}}$ \\
Caseína & $18,1 \pm 6,344^{\mathrm{c}, \mathrm{de}, \mathrm{f}}$ & $1,1 \pm 0,034^{\mathrm{f}}$ \\
Uréia & $25,3 \pm 7,535^{\mathrm{b}, \mathrm{d}, \mathrm{d}, \mathrm{e}}$ & $1,5 \pm 0,229^{\mathrm{c}, \mathrm{d}, \mathrm{e}}$ \\
Peptona & $29,7 \pm 2,517^{\mathrm{b}}$ & $2,2 \pm 0,035^{\mathrm{a}}$ \\
Controle & $19,7 \pm 4,452^{\mathrm{b}, \mathrm{c}, \mathrm{d}, \mathrm{f}}$ & $1,2 \pm 0,211^{\mathrm{c}, \mathrm{d}, \mathrm{e}}$ \\
\hline
\end{tabular}

As médias seguidas pela mesma letra não diferem entre si, a $5 \%$ de probabilidade, pelo teste de Tukey. da poligalacturonase, a concentração de $0,5 \%$ foi a que proporcionou maior atividade da enzima (Figura 2). Subsequentes aumentos na concentração da pectina cítrica não resultaram em acréscimo considerável na atividade da enzima, apesar do aumento observado no crescimento do microrganismo. Resultados semelhantes foram obtidos por Freitas (1991), que demonstrou que a produção de poligalacturonase por Penicillium expansum, inicialmente, cresceu com o aumento da concentração de pectina no meio, diminuindo em seguida, apesar de o fungo continuar crescendo.

A atividade da poligalacturonase variou grandemente em resposta à fonte de carbono utilizada no meio de cultura para o crescimento do microrganismo. A atividade da poligalacturonase foi significativamente maior durante o crescimento do microrganismo em pectina de maçã, seguida pela pectina cítrica. Por outro lado, foi menor em galactose, rafinose e glicose (Tabela 2). Resultados similares, mostrando um alto rendimento de pectinases com polímeros de pectina comparados com açúcares simples tais como arabinose, glicose e galactose, foram reportados por Said, Fonseca e Siessere (1991).

As fontes de carbono como a maltose, lactose, sacarose e manitol não foram efetivas na produção de poligalacturonase por Bacillus sp. Mg-cp-2. Além disso, neste mesmo microrganismo, a produção de poligalacturonase foi inibida por raminose, arabinose, glicose e galactose (KAPOOR et al., 2000).
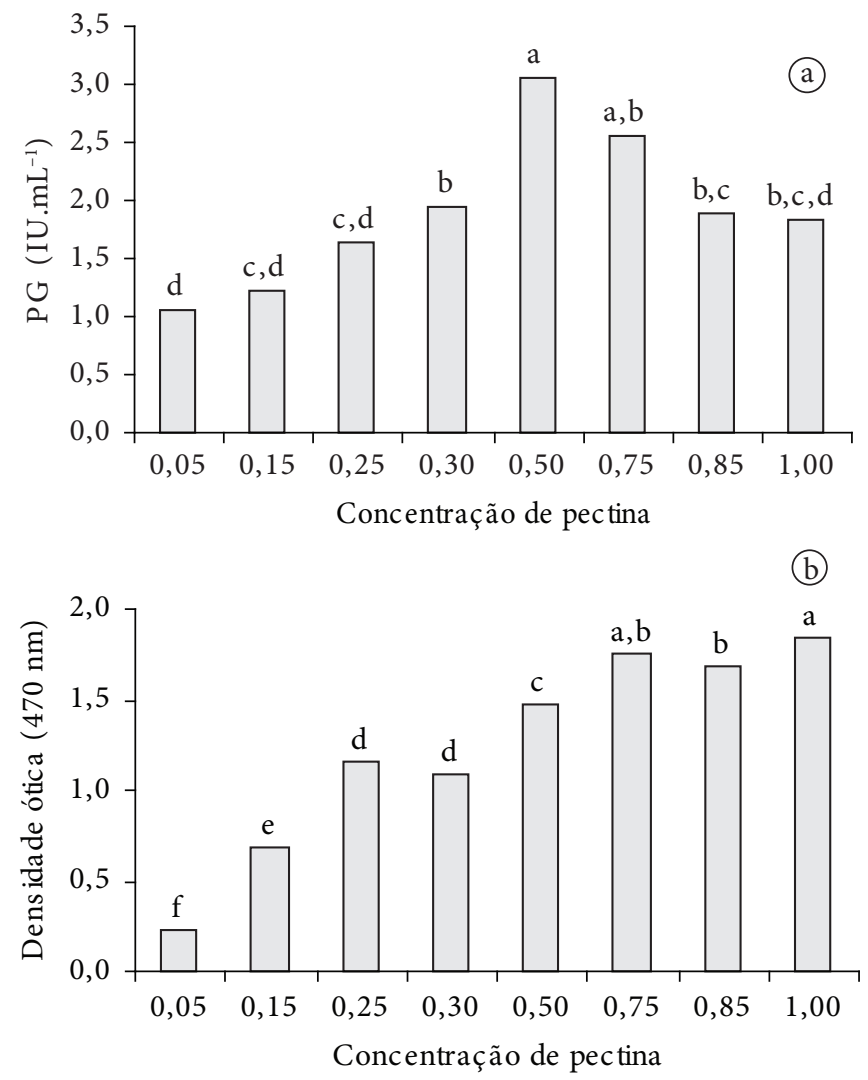

Figura 2. a) Influência da concentração da pectina cítrica no meio de cultura sobre a atividade da poligalacturonase e b) crescimento de Bacillus sp. SMIA-2. 


\subsection{Efeito da temperatura na atividade e estabilidade da poligalacturonase}

A atividade da poligalacturonase aumentou com a elevação da temperatura, atingindo seu valor máximo a $70{ }^{\circ} \mathrm{C}$ (32 IU.mL ${ }^{-1}$ ), conforme mostrado na Figura 2. Nas temperaturas de 40 e $90{ }^{\circ} \mathrm{C}$, a enzima apresentou $62 \%$ e $58 \%$ de sua atividade máxima, respectivamente. A poligalacturonase sintetizada por Therrmoascus aurantiacus apresentou atividade ótima à temperatura de $65^{\circ} \mathrm{C}$. À temperatura de $70^{\circ} \mathrm{C}$, essa enzima manteve em torno de $88 \%$ de sua atividade máxima (MARTINS et al., 2002). Bacillus sp. MG-cp-2 (KAPOOR et al., 2000) e Bacillus stearothermophilus (KARBASSI; VAUGHN, 1980) secretaram poligalacturonases cuja temperatura ótima para atividade da enzima foi 60 e $70^{\circ} \mathrm{C}$, respectivamente.

A poligalacturonase secretada por Bacillus sp. SMIA-2 manteve em torno de $70 \%$ de sua atividade quando incubada a $70^{\circ} \mathrm{C}$ por 2 horas e reduziu sua estabilidade com o aumento da temperatura. A poligalacturonase produzida por Thermoascus aurantiacus manteve $100 \%$ de sua atividade quando incubada a $60{ }^{\circ} \mathrm{C}$ por 2 horas. Entretanto, uma redução de $50 \%$ na atividade desta enzima foi observada, após a sua incubação a $70{ }^{\circ} \mathrm{C}$ por 2 horas (MARTINS et al., 2002).

\subsection{Efeito do pH na atividade e estabilidade de poligalacturonase}

A poligalacturonase foi ativa em uma ampla faixa de $\mathrm{pH}$, apresentando máxima atividade (23 IU.mL $\mathrm{mL}^{-1}$ ) em torno de $\mathrm{pH} 7,0$, como mostra a Figura 3. A atividade mais baixa da enzima foi encontrada em pH 5,5 e 9,5, que foram os valores mais extremos estudados. Resultados semelhantes foram encontrados por Soares, Silva e Gomes (1999), que investigaram o efeito do $\mathrm{pH}$ na atividade de poligalacturonase de várias estirpes de Bacillus sp. cultivado em fermentação semissólida (SSF). De acordo com estes autores, a maioria das estirpes estudadas apresentou $\mathrm{pH}$ ótimo para a atividade de poligalacturonase de 6,0. Apenas o Bacillus P4.3 apresentou pH ótimo entre 6,5 e 7,0. Kobayashi et al. (2001) encontraram para uma exopoligalacturonase produzida por Bacillus sp. estirpe KSM-P576 valor de pH ótimo igual a 8,0, enquanto Kapoor et al. (2000) encontraram um $\mathrm{pH}$ ótimo para a poligalacturonase produzida por Bacillus sp. MG-cp-2 igual a 10 (Figura 4).

Em relação à estabilidade do $\mathrm{pH}$, a poligalacturonase foi estável por 2 horas a valores de $\mathrm{pH}$ compreendidos entre 6,0-7,5. Quando incubada a pH 8,0 e 8,5, a enzima manteve $90 \%$ e $75 \%$

Tabela 2. Influência da fonte de carbono sobre o crescimento de Bacillus sp. SMIA-2 e a atividade da poligalacturonase.

\begin{tabular}{lcc}
\hline Fonte de carbono & $\begin{array}{c}\text { Atividade máxima da } \\
\text { enzima }\left(I U \cdot \mathrm{mL}^{-1}\right)\end{array}$ & $\begin{array}{c}\text { Densidade ótica } \\
(470 \mathrm{~nm})\end{array}$ \\
\hline Pectina de maçã & $56,1 \pm 16,085^{\mathrm{a}}$ & $1,3 \pm 0,025^{\mathrm{a}, \mathrm{b}}$ \\
Pectina cítrica & $38,5 \pm 3,303^{\mathrm{b}}$ & $1,5 \pm 0,206^{\mathrm{a}}$ \\
Frutose & $25,4 \pm 9,132^{\mathrm{c}}$ & $1,1 \pm 0,005^{\mathrm{b}}$ \\
Maltose & $22,3 \pm 4,794^{\mathrm{c}, \mathrm{d}}$ & $1,9 \pm 0,005^{\mathrm{c}}$ \\
Galactose & $15,4 \pm 4,227^{\mathrm{d}, \mathrm{e}}$ & $2,2 \pm 0,087^{\mathrm{c}}$ \\
Rafinose & $11,7 \pm 2,323^{\mathrm{e}}$ & $2,1 \pm 0,050^{\mathrm{c}}$ \\
Glicose & $11,4 \pm 1,142^{\mathrm{e}}$ & $1,3 \pm 0,277^{\mathrm{a}, \mathrm{b}}$ \\
\hline
\end{tabular}

As médias seguidas pela mesma letra não diferem entre si, a $5 \%$ de probabilidade, pelo teste de Tukey. de sua atividade, respectivamente. Uma exo-poligalacturonase produzida por Bacillus sp. strain KSM-P576 foi estável por 1 hora a valores de $\mathrm{pH}$ compreendidos entre 6 e 12 (KOBAYASHI et al., 2001). Já a poligalacturonase produzida por Bacillus sp. MG-cp-2 foi estável por 24 horas na faixa de $\mathrm{pH}$ de 7 a 12 retendo mais de $80 \%$ de sua atividade (KAPOOR et al., 2000).

\subsection{Efeito de alguns íons metálicos sobre a atividade da poligalacturonase}

A atividade da poligalacturonase foi estimulada pelos íons $\mathrm{Mg}^{+2}$ e $\mathrm{Zn}^{+2}$ como mostrado na Figura 5. Por outro lado, foi inibida pelos íons $\mathrm{Cs}^{+2}, \mathrm{Hg}^{+2}, \mathrm{Li}^{+2} \mathrm{e} \mathrm{Sr}^{+2}$. A poligalacturonase

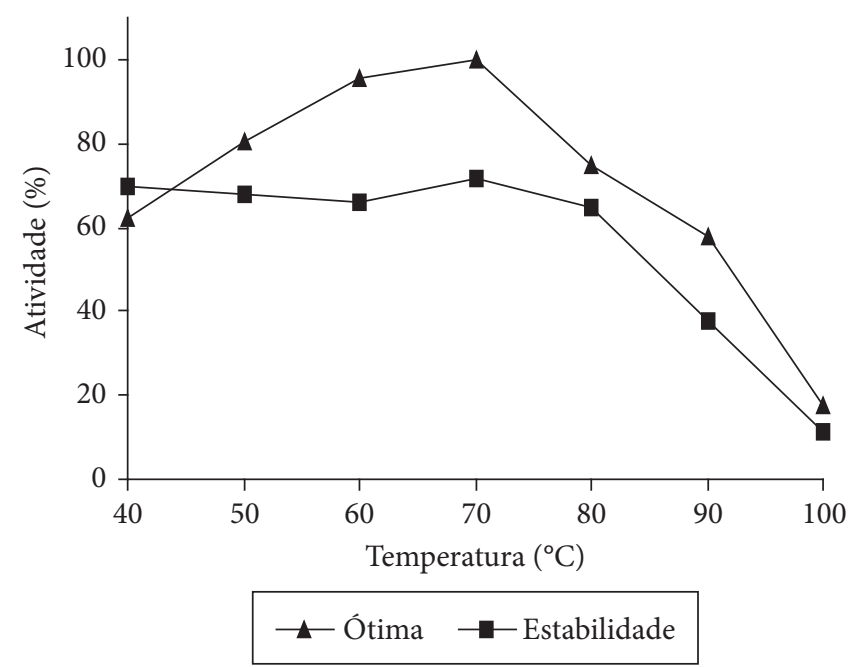

Figura 3. Temperatura ótima e estabilidade térmica da poligalacturonase secretada por Bacillus sp. SMIA-2, crescido em meio mineral contendo $0,5 \%$ de pectina de maçã por 48 horas a $50{ }^{\circ} \mathrm{C}(100 \%$ de atividade $=32 \mathrm{IU} \cdot \mathrm{mL}^{-1}$ ).

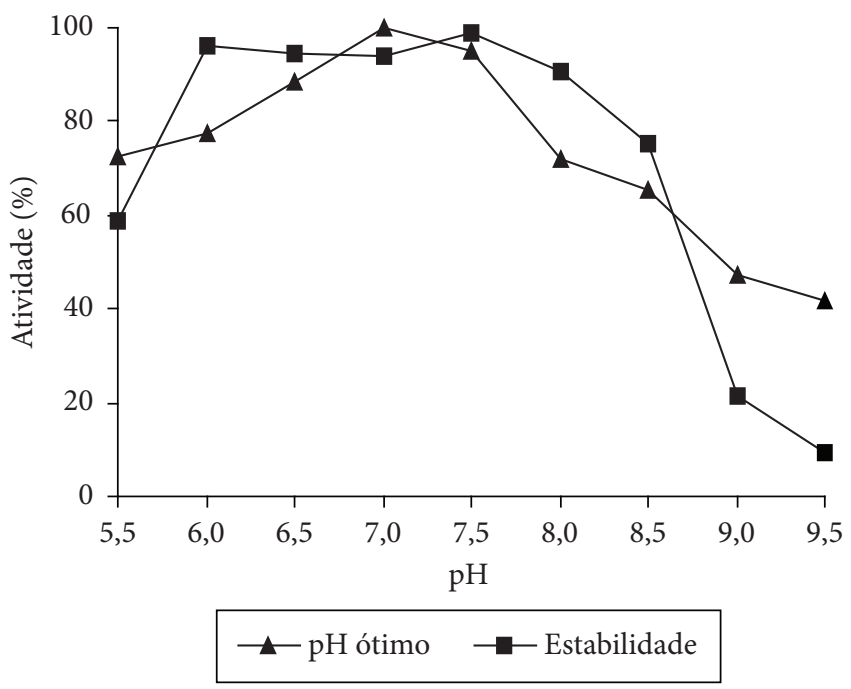

Figura 4. Influência do $\mathrm{pH}$ sobre a atividade e estabilidade da poligalacturonase secretada por Bacillus sp. SMIA-2 cultivado em meio mineral contendo $0,5 \%$ de pectina de maçã por 48 horas a $50^{\circ} \mathrm{C}(100 \%$ de atividade enzimática $=23$ IU.mL $\mathrm{mL}^{-1}$ ). 


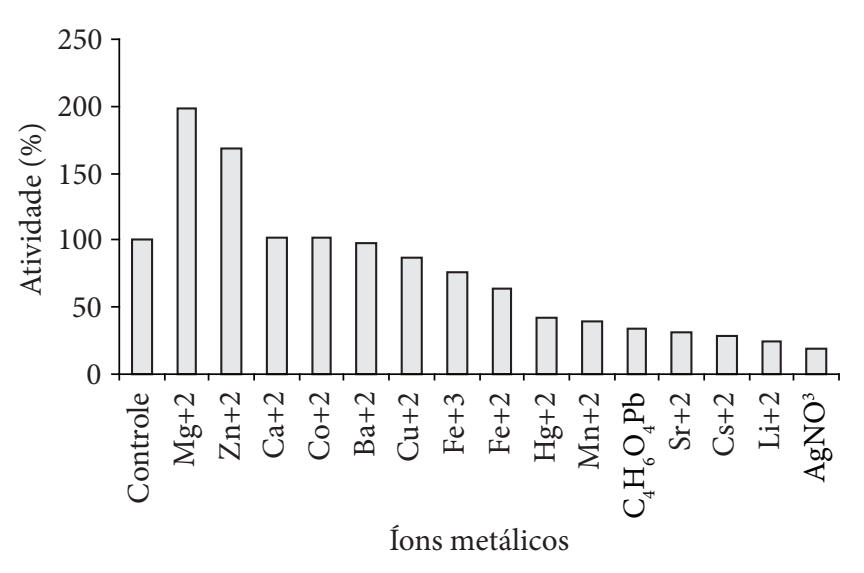

Figura 5. Efeito de diferentes íons metálicos na atividade da poligalacturonase de Bacillus sp. SMIA-2 cultivado em meio mineral contendo $0,5 \%$ de pectina de maçã por 48 horas a $50{ }^{\circ} \mathrm{C}$. O controle (ausência de metais) foi considerado como $100 \%$ da atividade enzimática $=18 \mathrm{IU} \cdot \mathrm{mL}^{-1}$.

secretada por Bacillus sp. KSM-P576 foi também estimulada por $\mathrm{Mg}^{+2}$. Na presença deste íon, foi observado um aumento de $160 \%$ na atividade da poligalacturonase. Por outro lado, os íons $\mathrm{Zn}^{+2} \mathrm{e} \mathrm{Cu}^{+2}$ inibiram a atividade da enzima em 94 e $69 \%$ respectivamente (KOBAYASHI et al., 2001).

$\mathrm{O} \mathrm{Mg}^{+2}$ também estimulou a atividade da poligalacturonase produzida por Aspergillus carbonarius (DEVI; RAO, 1996), mas inibiu a atividade da poligalacturonase produzida por Bacillus sp. RK9 (KELLY; FOGARTY, 1978). Em Bacillus sp. MG-cp-2, os íons $\mathrm{Ca}^{+2}, \mathrm{Ba}^{+2}, \mathrm{Co}^{+2} \mathrm{e} \mathrm{Li}^{+2}$ estimularam a atividade da poligalacturonase, enquanto os íons $\mathrm{Mn}^{+2}, \mathrm{Hg}^{+2} \mathrm{e}_{4} \mathrm{H}_{6} \mathrm{O}_{4} \mathrm{~Pb}$ inibiram a sua atividade (KAPOOR et al., 2000). De acordo como Tomazic (1991), a estabilização de algumas enzimas pode ser induzida por aditivos não proteicos, principalmente íons bivalentes como $\mathrm{Ca}^{+2}, \mathrm{Mn}^{+2}, \mathrm{Zn}^{+2} \mathrm{e} \mathrm{Mg}^{+2}$. Esses íons, usados em baixas concentrações, podem favorecer a estrutura terciária da proteína promovendo a formação de ligações cruzadas, que conferem a ela uma maior estabilidade.

\section{Conclusões}

A maior atividade da poligalacturonase (56 IU. $\left.\mathrm{mL}^{-1}\right)$, secretada por Bacillus sp SMIA-2, é obtida quando este é cultivado em um meio contendo $0,5 \%$ de pectina de maçã como fonte de carbono e $1 \%$ de sulfato de amônio como fonte de nitrogênio.

A temperatura e o $\mathrm{pH}$ ótimos para a atividade da poligalacturonase foram $70{ }^{\circ} \mathrm{C}$ e 7,0 , respectivamente. A atividade enzimática é estimulada pelos íons $\mathrm{Mg}^{2+} \mathrm{e} \mathrm{Zn}^{2+} \mathrm{e}$ inibida pelos íons $\mathrm{Cs}^{+2}, \mathrm{Hg}^{+2}, \mathrm{Li}^{+2}$ e $\mathrm{Sr}^{+2}$.

\section{Referências bibliográficas}

AGUILAR, A. Extremophile research in the European Union: from fundamental aspects to industrial expectations. FEMS Microbiology Reviews, v. 18, n. 1, p. 89-92, 1996.
ARCHANA, A.; SATYANARAYANA, T. Xylanase production by thermophilic Bacillus licheniformis A99 in solid-state fermentation. Enzyme and Microbial Technology, v.21, n. 1, p.12-17, 1997.

BRAVO, C. E. C. et al. Determinação de condições ideais para a produção de poligalacturonase por Kluyveromyces marxianus. Ciência e Agrotecnologia, v. 24, n. 1, p. 137-152, 2000.

BRUINS, M. E.; JANSSEN, A. E.; BOOM, R. M. Thermozymes and their applications: a review of recent literature and patentes. Applied Biochemistry and Biotechnology, v. 90, n. 2, p. 155-186, 2001.

BUENROSTRO, M.; LOPES-MUNGUIA, A. Enzimatic extraction of avocado oil. Biotechnology Letters, v. 8, n. 4, p. 505-506, 1986.

CONTRERAS-ESQUIVEL, C. J. C.; VOGET, C. E. Purification and partial characterization of an acidic polygalacturonase from Aspergillus kawachii. Journal of Biotechnology, v. 110, n. 1, p. 21-26, 2004.

DEVI, N. A.; RAO, A. G. A. Fractionation, purification, and preliminary characterization of polygalacturonase produced by Aspergillus carbonarius. Enzyme and Microbial Technology, v. 18, n. 1, p. 59-65, 1996.

EVANS, C. G. T.; HERBERT, D.; TEMPEST, D. W. The continuous cultivation of microorganisms. 2. Construction of a chemostat. Methods in Microbiology, v. 2, n. 3, p. 275-327, 1970.

FAWOLE, O. B.; ODUNFA, S. A. Some factors affecting production of pectic enzymes by Aspergillus niger. International Biodeterior Biodegradation, v. 52, n. 2, p. 223-227, 2003.

FREITAS, L. E. Produção e caracterização parcial de poligalacturonase de Penicillium expansum. Viçosa, 1991. 66p. Dissertação (Mestrado em Microbiologia Agrícola), Universidade Federal de Viçosa - UFV.

GENARI, R. Características de crescimento e produção de pectinases por Klebsiela oxytoca isolada de frutos de café. Viçosa, 1999. 90p. Dissertação (Mestrado em Microbiologia Agrícola), Universidade Federal de Viçosa - UFV.

GHILDYAL, N. P. et al. Large scale production of pectolytic enzyme by solid state fermentation. Journal Food Science Technology, v. 18, n. 2, p. 248-251, 1981.

GUPTA, S. et al. Production and recovery of an alkaline exopolygalacturonase from Bacillus subtilis RCK under solid-state fermentation using statistical approach. Bioresource Technology, v. 98, n. 7, p. 2969-3180, 2007.

HAKI, G. D.; RAKSHIT, S. K. Developments in industrially important thermostable enzymes: a review. Bioresource Technology, v. 89, n. 1, p. 17-34, 2003.

KAPOOR, M. et al. Production and partial purification and characterization of a thermo-alkali stable polygalacturonase from Bacillus sp. MG-cp-2. Process Biochemistry, v. 36, n. 3, p. 467-473, 2000.

KARBASSI, A.; VAUGHN, R. H. Purification and properties of polygalacturonic acid trans-eliminase from Bacillus stearothermophilus. Canadian Journal Microbiology, v. 26, n. 2, p. 377-384, 1980.

KASHYAP, D. R. et al. Applications of pectinases in the commercial setor: a review. Bioresource Technology, v. 77, n.2, p. 215-227, 2001.

KELLY, C.; FOGARTY, W. M. Production and properties of polygalacturonate lyase by an alkalophilic microorganism Bacillus sp. RK9. Canadian Journal Microbiology, v. 24, n. 7, p. 1164-1172, 1978. 
KOBAYASHI, T. et al. Purification and properties of a high-molecularweight, alkaline exopolygalacturonase from a strain of Bacillus. Enzyme and Microbial Technology, v. 29, n. 1, p. 70-75, 2001.

LEE, D. W. et al. Purification and characterization of two thermostable lipases from the gram-positive thermophilic bacterium Bacillus thermoleovorans ID-1. Enzyme and Microbial Technology, v. 29, n. 2, p. 363-371, 2001.

MARTINS, E. S. et al. Solid state of thermostable pectinases from thermophilic Thermoascus auruntiacus. Process Biochemistry, v. 37, n. 6, p. 949-954, 2002.

MILLER, G. L. Use of dinitrosalicylic acid reagent for determination of reducing sugar. Analitical Biochemistry, v. 31, n. 2, p. 426-428, 1959.

MING CHU, I.; LEE, C.; LI, T. S. Production and degradation of alkaline protease in batch cultures of Bacillus subtilis ATCC 14416. Enzyme and Microbial Technology, v. 14, n. 4, p. 755-761, 1992.

NIGHOJKAR, S. et al. Production of polygalacturonase by immobilized cells of Aspergillus niger using orange peel as inducer. Process Biochemistry, v. 41, n. 6, p. 1136-1140, 2006.

NITURE S. K.; PANT, A. Purification and biochemical characterization of polygalacturonase II produced in semi-solid medium by a strain of Fusarium moniliforme. Microbiology Resource, v. 159, n. 3, p. 305-314, 2004.

NUNES, A. S.; MARTINS, M. L. L. Isolation, properties and kinetics of growth of a thermophilic Bacillus. Brazilian Journal of Microbiology, v. 32, n. 2, p. 271-275, 2001.

SAID, S.; FONSECA, M. J. V.; SIESSERE, V. Pectinase production by Penicillium frequentans. World Journal Microbiology Biotecnology, v. 7, n. 5, p. 607-608, 1991.

SAKAI, T. et al. Pectin, pectinase, and protopectinase: production, properties, and applications. Advances in Applied microbiology, v. 39, n. 2, p. 213-294, 1993.

SOARES, M. M. C. N.; SILVA, R.; GOMES, E. Screening of bacterial strains for pectinolutic activity: characterizations of the polygalacturonase produced by Bacillus sp. Revista de Microbiologia, v. 30, n. 3, p. 299-303, 1999.

TOMAZIC, S. J. Protein Stabilization. Topic in Applied Chemistry. New York: Ed. Plenum Press, 1991.

USTOK, F. I.; TARI, C.; GOGUS, N. Solid-state production of polygalacturonase by Aspergillus sojae ATCC 20235. Journal of Biotechnology, v. 127, n. 2, p. 322-334, 2007. 